\title{
Recent Advances in Understanding Gadolinium Retention in the Brain
}

W e wish to comment on the August 2015 article of Adin et al ${ }^{1}$ in the American Journal of Neuroradiology (AJNR) entitled "Hyperintense Dentate Nuclei on T1-Weighted MRI: Relation to Repeat Gadolinium Administration." The authors reported the relationship between the hyperintense dentate nucleus on unenhanced T1WI and past gadolinium based-contrast agent (GBCA) administration. This relationship was first reported by our group on December 7, 2013. ${ }^{2}$ Since then, several important reports have been published, and knowledge regarding gadolinium deposition has increased remarkably.

Our group ${ }^{3}$ and Radbruch et $\mathrm{al}^{4}$ evaluated the difference in the signal change between patients repeatedly administered linear GBCA and macrocyclic GBCA. A change in the signal intensity of the dentate nucleus was observed in the former, but not in the latter. McDonald et $\mathrm{al}^{5}$ and our group ${ }^{6}$ evaluated the brain tissue from postmortem specimens, and gadolinium deposition was verified from the brain tissue. ${ }^{7}$ Robert et $\mathrm{al}^{8}$ injected GBCA 20 times into rats and evaluated the signalintensity change of the dentate nucleus on T1WI and gadolinium concentration in the brain. A hyperintense dentate nucleus was observed in rats with repeat linear GBCA administration, but not with repeat macrocyclic GBCA administration. The gadolinium concentration of the brain with repeat linear GBCA administration was 14 times greater than that with repeat macrocyclic GBCA administration. ${ }^{8}$ The work of Adin et $\mathrm{al}^{1}$ was confirmed in our first study. It was accepted by AJNR on February 19, 2015, and was published on-line on August 20, 2015. In this short period, studies on gadolinium deposition advance so rapidly, a more prompt publication schedule from $A J N R$ would be desirable.

In previous studies (our study), a hyperintense dentate nucleus on T1WI was detected in subjects with $>5$ previous administrations of gadodiamide or gadopentetate dimeglumine. In contrast, in this study, some of the subjects with $>12$ previous administrations of GBCA did not show hyperintensity in the dentate nucleus. One reason may be the use of macrocyclic GBCAs in these subjects. In addition, the detectability of the

- Indicates open access to non-subscribers at www.ajnr.org

http://dx.doi.org/10.3174/ajnr.A4586
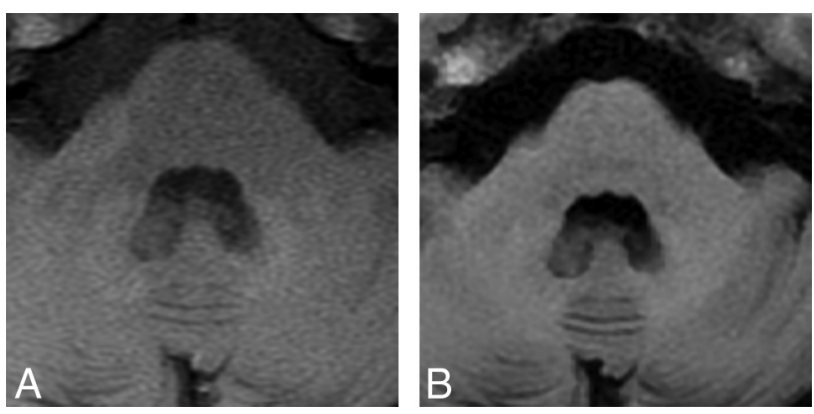

FIG 1. Images in a 41-year-old woman with a history of malignant lymphoma and 7 administrations of gadopentetate dimeglumine. The dentate nucleus is hyperintense on spin-echo TIWI $(A)$, but not on TI FLAIR (B).

hyperintense dentate nucleus on various sequences of T1WI may have influenced their results. According to our experience with several cases, the detectability of high signal intensity in the dentate nucleus differs between spin-echo T1WI and T1 FLAIR (Fig 1). Adin et $\mathrm{al}^{1}$ evaluated the hyperintense dentate nucleus with various T1WI sequences, such as MPRAGE, spinecho, and T1 FLAIR. The different detectabilities of hyperintense dentate nuclei on these sequences may have influenced their results.

\section{REFERENCES}

1. Adin ME, Kleinberg L, Vaidya D, et al. Hyperintense dentate nuclei on T1-weighted MRI: relation to repeat gadolinium administration. AJNR Am J Neuroradiol 2015 Aug 20. [Epub ahead of print] CrossRef Medline

2. Kanda T, Ishii $\mathrm{K}$, Kawaguchi $\mathrm{H}$, et al. High signal intensity in the dentate nucleus and globus pallidus on unenhanced T1-weighted MR images: relationship with increasing cumulative dose of a gadolinium-based contrast material. Radiology 2014;270:834-41 CrossRef Medline

3. Kanda $\mathrm{T}$, Osawa $\mathrm{M}$, Oba $\mathrm{H}$, et al. High signal intensity in dentate nucleus on unenhanced T1-weighted MR images: association with linear versus macrocyclic gadolinium chelate administration. $R a$ diology 2015;275:803-09 CrossRef Medline

4. Radbruch A, Weberling LD, Kieslich PJ, et al. Gadolinium retention in the dentate nucleus and globus pallidus is dependent on the class of contrast agent. Radiology 2015;275:783-91 CrossRef Medline

5. McDonald RJ, McDonald JS, Kallmes DF, et al. Intracranial gadolinium deposition after contrast-enhanced MR imaging. Radiology 2015;275:772-82 CrossRef Medline 
6. Kanda T, Fukusato T, Matsuda M, et al. Gadolinium-based contrast agent accumulates in the brain even in subjects without severe renal dysfunction: evaluation of autopsy brain specimens with inductively coupled plasma mass spectroscopy. Radiology 2015;276: 228-32 CrossRef Medline

7. Kanal E, Tweedle MF. Residual or retained gadolinium: practical implications for radiologists and our patients. Radiology 2015;275: 630-34 CrossRef Medline

8. Robert P, Lehericy S, Grand S, et al. T1-weighted hypersignal in the deep cerebellar nuclei after repeated administrations of gad- olinium-based contrast agents in healthy rats: difference between linear and macrocyclic agents. Invest Radiol 2015;50: 473-80 CrossRef Medline

(1) T. Kanda

(1) H. Oba

(D) K. Toyoda

(D). Furui

Department of Radiology

Teikyo University School of Medicine

Itabashi-ku, Japan 